\title{
Estimation of body weight by an indirect measurement method in developing replacement Holstein heifers raised on pasture ${ }^{\#}$
}

\author{
Estimación del peso corporal mediante un método indirecto \\ en vaquillonas Holstein de reposición criadas sobre pasturas
}

\author{
G Bretschneider*, A Cuatrin, D Arias, D Vottero \\ Instituto Nacional de Tecnología Agropecuaria (INTA), Estación Experimental Agropecuaria (EEA)-Rafaela, Santa Fe, Argentina.
}

\begin{abstract}
RESUMEN
El método más preciso para medir el peso corporal (BW) es la balanza. Sin embargo, cuando la misma no está disponible son necesarios métodos indirectos para estimar el BW. El objetivo de este estudio fue evaluar la distancia entre la tuberosidad coxal izquierda y derecha (DLRCT) como potencial estimador del BW desbastado (SBW) de vaquillonas Holstein en desarrollo, las que fueron pesadas simultáneamente con una balanza electrónica. El estudio incluyó hembras Holstein Argentino preservicio de 3 a 21 meses de edad. Se usaron 496 observaciones para cuantificar la relación entre la DLRCT $(\mathrm{cm})$ y el SBW $(\mathrm{kg})$ por el método de los cuadrados mínimos. La función exponencial Y $=0,131 \mathrm{X}^{2,0758}$, donde $\mathrm{X}=$ DLRCT tuvo el mejor ajuste $(\mathrm{P}<0,0001)$ para predecir el SBW. Se emplearon 194 observaciones para validar la función. El coeficiente de correlación de Lin fue 0,97 y el IC 95\% fue 0,965-0,979. La diferencia media entre el valor observado y estimado del SBW fue $-0,99 \mathrm{~kg}$. No hubo diferencias significativas $(t=-0,83$; $\mathrm{P}=0,41$ ) entre la media observada y estimada del SBW. Como un estimador del SBW, particularmente en vaquillonas $\geq 5$ meses de edad y $\leq 350 \mathrm{~kg}$ BW (i.e. $\leq 45 \mathrm{~cm}$ ), la DLRCT demostró ser una alternativa útil que puede ser usada fácilmente durante cualquier práctica habitual realizada sobre las vaquillonas en desarrollo, sin necesidad de instalaciones especiales para la sujeción ni el manipuleo del ganado.
\end{abstract}

Palabras clave: vaquillonas lecheras, peso corporal, crecimiento, Holstein.

\section{SUMMARY}

Scale is the most accurate means of measuring the actual body weight (BW) in developing heifers. However, when it is not available, indirect tools to estimate BW are needed. The objective of this study was to evaluate the distance between the left and right coxal tuberosity (DLRCT) as potential estimator of shrunk BW (SBW) of developing Holstein heifers as compared with the actual weight measured by an electronic scale. The study included pre-breeding Argentinean Holstein females from 3 to 21 months of age. A dataset comprising 496 observations was used to quantify the relationship between the DLRCT $(\mathrm{cm})$ and the SBW $(\mathrm{kg})$ by the least squared method. The power function $\mathrm{Y}=0.131 \mathrm{X}^{2.0758}$, where $\mathrm{X}=$ DLRCT provided the best fit $(\mathrm{P}<0.0001)$ for predicting SBW. A dataset comprising 194 observations was used to assess the strength of agreement of the power function. The Lin correlation coefficient value was 0.97 and the computed $95 \%$ CI was $0.965-0.979$. The mean difference between observed and estimated SBW was $-0.99 \mathrm{~kg}$. There was no significant difference $(\mathrm{t}=-0.83 ; \mathrm{P}=0.41)$ in the mean SBW between observed and estimated data. As a predictor of SBW, particularly in heifers $\geq 5$ months of age and $\leq 350 \mathrm{~kg}$ BW (i.e. $\leq 45 \mathrm{~cm}$ ), the DLRCT demonstrated to be a useful alternative that can be easily applied during any practice usually performed on replacement heifers, without requiring a squeeze chute.

Key words: dairy heifers, body weight, growth, Holstein.

\section{INTRODUCTION}

The replacement heifer is the next generation of genetic progress for the dairy herd. The interest in rearing heifers is mainly due to the feeding cost, which represents approximately $53 \%$ of the rearing investment, and the impact of the growing period on lifetime milk production (Heinrichs and Swartz 1990, NRC 2001). Overall, farmers make significant investments in their future dairy cows, even if they fail to conceive. Therefore, to obtain a return on

\footnotetext{
Accepted: 26.12.2013.

\# SANFE-1261102. Desarrollo territorial sustentable de la zona mixta de la provincia de Santa Fe, Argentina.

* bretschneider.g@inta.gob.ar; bretschneider3@hotmail.com
}

this investment, it is imperative that these heifers become pregnant as soon as possible, calve without assistance, breed back on time, and then continue to be productive for many years (Engelken 2008).

In order to optimise profitability, heifers should calve and enter the milking herd at 22 to 24 months old. This goal requires proper health and nutrition management programs that ensure an adequate body size to breed heifers between 13 and 15 months of age (Heinrichs and Lammers 1998). The body size (skeletal development) of replacement heifers is normally characterised as body weight (BW) (Hoffman 1997; Enevoldsen and Kristensen 1997). Dairy heifers should be bred at about $55 \%$ of mature shrunk BW i.e. $0.96 \mathrm{x}$ mature BW, which is equivalent to an animal's weight following an overnight fast (NRC 2001). 
Across the world, many commercial dairy farms do not have cattle weighing scales. Under this scenario, researchers have developed indirect methods to estimate BW of Holstein replacement heifers by equations (Heinrichs et al 1992) or calibrated tools (Dingwell et al 2006) from various body measurements. As indicators of skeletal development, these measurements (e.g. heart girth, wither height, hip height, etc.) are relatively simple to obtain due to their easily identifiable anatomical locations (Enevoldsen and Kristensen 1997). However, to monitor the growth of heifers by these indirect methods, dairy farms must count with complete restraining and handling systems for protecting cattle and operators from injuries.

In most small and medium-sized Argentinean dairy farms, where grazed pastures represent an important component of year-round feeding, facilities for cattle handling and working are generally limited. Empirical evidence suggests that the distance between the left and right coxal tuberosity (DLRCT) is an easily accessible measurement to take without requiring either complete restraint or manipulation of heifers. The objective of this study was to evaluate the DLRCT as potential estimator of shrunk BW (SBW) of developing Argentinean Holstein heifers as compared with the actual weight measured by an electronic scale.

\section{MATERIAL AND METHODS}

\section{EXPERIMENTAL ANIMALS AND DIET}

Data were collected from the research dairy herd of the National Institute of Agricultural Technology, Rafaela, province of Santa Fe, Argentina ( $31^{\circ} 12^{\prime} \mathrm{S} ; 61^{\circ} 30^{\prime} \mathrm{W}$ ). For the purpose of this article the term heifer refers to females from 3 months old to sexually mature but which are not yet involved in breeding. The study included developing Argentinean Holstein heifers from 3 to 21 months of age. Heifers were assigned to two age-groups for grazing alfalfa pastures. Concurrently, at a feed bunk, they were fed a mixture of cracked grain corn and sorghum silage. At all times, heifers had free access to water as well as to alfalfa hay fed in a round bale feeder.

\section{EXPERIMENTAL PROCEDURE}

Data recordings started on April 2011. On scheduled days, data were collected in the morning before feeding. Overnight, all animals had been held off feed and water. Once each heifer was individually allowed to enter into a squeeze chute, both DLRCT and SBW measurements were recorded. The DLRCT (i.e. width of hook bones) was measured using a long, straight, graduated scale $(\mathrm{cm})$ equipped with two crossbars. On one end, the scale has a fixed crossbar, whereas the other crossbar slides over the scale and moves in either direction until fitting in both hook bones (figure 1). Thereafter, every animal was weighed

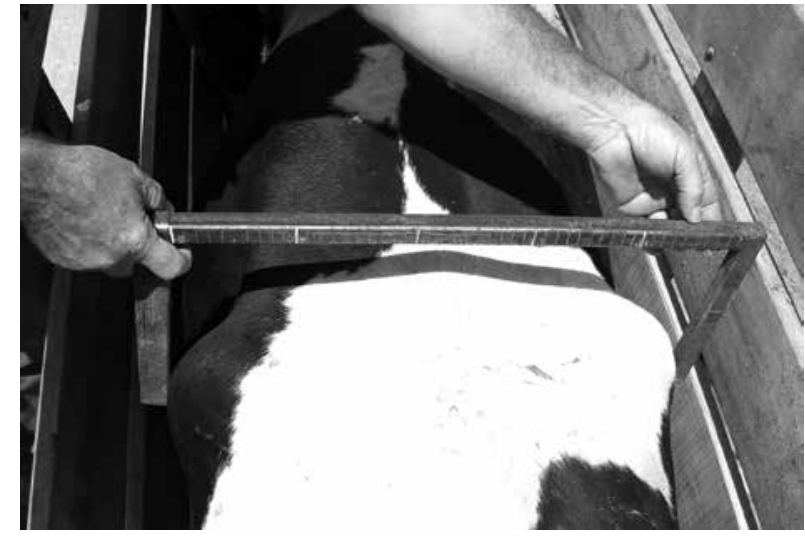

Figure 1. Placement of the tool used to measure the distance between the left and right coxal tuberosity (hook bone) to estimate the shrunk body weight $(\mathrm{kg})$ of developing replacement Holstein heifers.

Posición de la herramienta para la medición de la distancia entre las tuberosidades coxales, utilizada para estimar el peso corporal desbastado $(\mathrm{kg})$ de vaquillonas Holstein para reposición.

$(\mathrm{kg})$ using an electronic scale, which was calibrated before weighing. All measurements were obtained by the same technician on a single day, every 30 days. The number of paired recordings performed on each heifer varied from one to four.

\section{STATISTICAL ANALYSIS}

A dataset comprising 496 observations obtained from 262 heifers from 3 to 21 months of age was used to quantify the relationship between the DLRCT $(\mathrm{cm})$ and the SBW $(\mathrm{kg})$. Nonlinear regression models were fitted by the least squared technique using the convergence analysis of the Gauss-Newton method (PROC NLIN, SAS, 2004). Based on it, the power function provided the best fit for predicting SBW. The regression model was as follow:

$$
\mathrm{Y}_{\mathrm{ij}}=\mathrm{aX}_{\mathrm{ij}}^{\mathrm{b}}+\mathrm{e}_{\mathrm{ij}}
$$

Where $\mathrm{Y}_{\mathrm{ij}}=$ the SBW $(\mathrm{kg})$ of the $\mathrm{i}^{\mathrm{th}}$ animal in the $\mathrm{j}^{\text {th }}$ sampling day, $\mathrm{a}=$ constant, $\mathrm{X}_{\mathrm{ij}}=$ the DLRCT $(\mathrm{cm})$ of the $\mathrm{i}^{\text {th }}$ animal in the $\mathrm{j}^{\text {th }}$ sampling day, $\mathrm{b}=$ constant, and $\mathrm{e}_{\mathrm{ij}}=$ error term, normally distributed with zero mean and known variance.

A dataset comprising 194 observations obtained from 186 heifers from 5 to 21 months of age was used to assess the strength of agreement of the power function. To achieve this goal, two sets of analysis were performed. The Lin concordance correlation coefficient to determine whether observed and estimated SBW deviated significantly from the $45^{\circ}$ line of perfect concordance. Any departure from it will result in a concordance less than one (Lin 1989). The Blant-Altman method was used to graph the difference versus the mean of pairs of weights (observed and 
estimated) registered from each heifer, thus allowing the visualisation of differences between the two sets of measurements (Altman and Bland 1983). Data were analysed using the $\mathrm{R}$ (version 2.15.1) program. In addition, a paired t-test was used to test that the average of the differences between the paired observations of the two BW assessment methodologies was zero (PROC TTEST, SAS 2004). A $5 \%$ significance level was used.

\section{RESULTS AND DISCUSSION}

For model development, the relationship between the DLRCT (cm) and the actual SBW (kg) was quantified by the least squared method. As shown in figure 2, the power model provided significantly better fit $(\mathrm{P}<0.0001)$ than other regression functions. The power equation was: $\mathrm{Y}=$ $0.131 \mathrm{X}^{2.0758}$, where $\mathrm{Y}=\mathrm{SBW}(\mathrm{kg})$ and $\mathrm{X}=\operatorname{DLRCT}(\mathrm{cm})$. The standard error (SE) of the estimate (SE estimate) was computed to assess the accuracy of the prediction. As a measure of dispersion, the SE estimate described herein was $15.94 \mathrm{~kg}$ (i.e. $5.77 \%$ of the mean of SBW). Overall, the results indicate that the SBW of replacement dairy heifers can be accurately predicted from the DLRCT. Like many other measurements such as hip width, wither height, and heart girth already described as accurate methods to predict BW (Heinrichs et al 1992, Dingwell et al 2006), the DLRCT attempts to define skeletal development (body size). Hoffman (1997) pointed out that because BW is influenced by body condition score (BCS), anatomical measurements, as indicators of skeletal size, may reflect the true size of replacement heifers better than BW. According to Dingwell et al (2006), BCS would be relevant in developed rather than developing heifers. In the former, differences in BW and body size would be mainly due to BCS.

For model validation, the strength of agreement between the actual and predicted SBW was assessed. On one hand, the Lin concordance correlation was performed (figure 3). The correlation coefficient value was 0.97 . As indicator of the Lin coefficient's reliability, the $95 \%$ CI (0.965 - 0.979) was computed. On the other hand, the Bland-Altman graph was constructed and visually analyzed. As shown in figure 4 , the mean difference between observed and estimated SBW was $-0.99 \mathrm{~kg}$. The $95 \%$ limits of agreement (mean difference $\pm 2 \mathrm{SD}$ difference) were $-34.2 \mathrm{~kg}$ to + $32.2 \mathrm{~kg}$. There was no significant difference $(\mathrm{t}=-0.83 ; \mathrm{P}=$ $0.41)$ in the mean SBW, as recorded by the electronic scale (mean $\pm \mathrm{SD} ; 276.2 \pm 73.7)$ and as estimated by the DLRCT (277.2 \pm 67.0$)$. The model validation results support the estimation of SBW from the DLRCT as an alternative to electronic scale. However, it is important to make some considerations with regard to the scope of usage of the

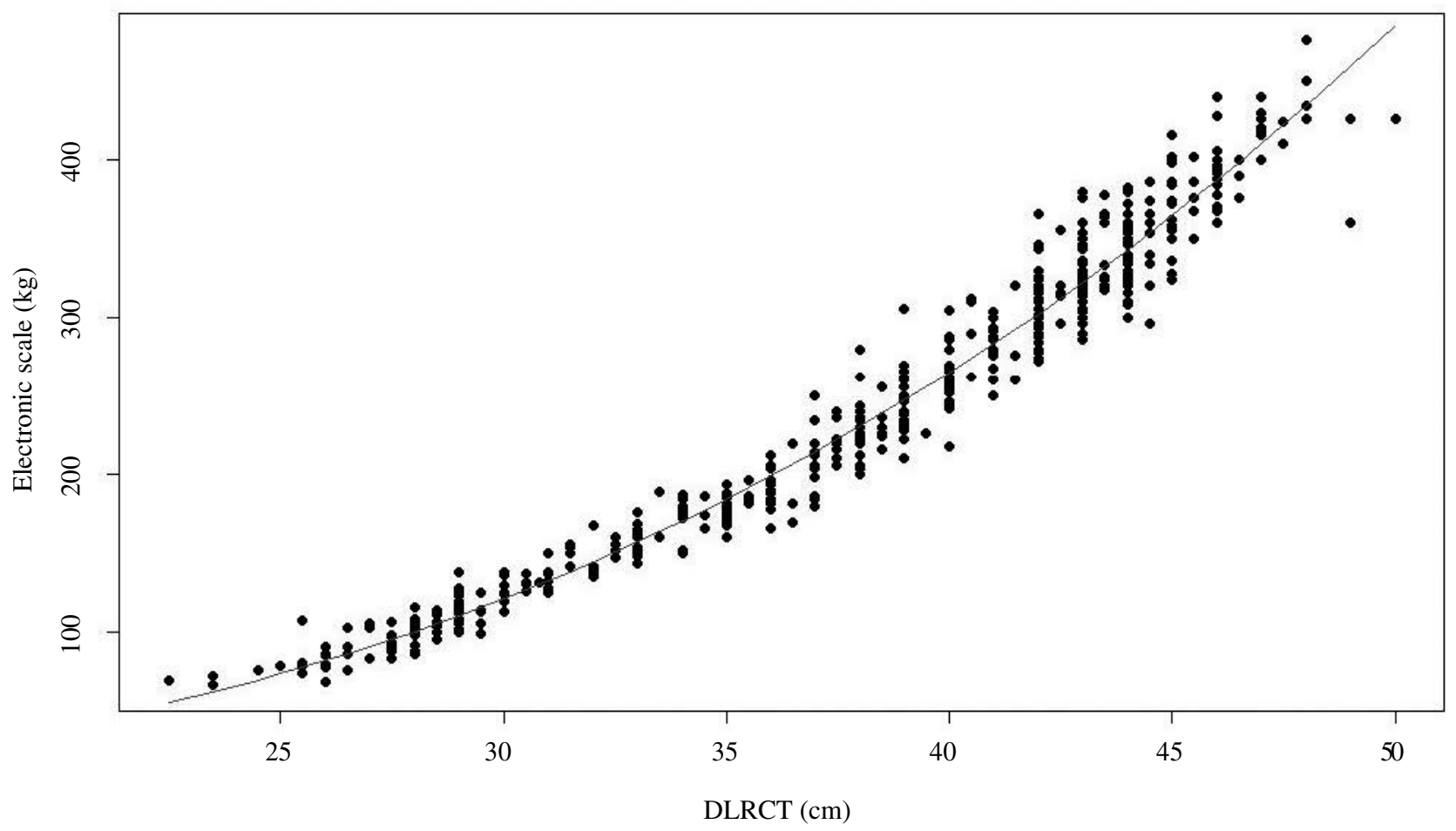

Figure 2. Power fit of the shrunk body weight recorded by electronic scale (kg) as function of the distance between the left and right coxal tuberosity (DLRCT; cm). This graph was constructed from 496 observations. Regression equation was $\mathrm{Y}=0.131 \mathrm{X}^{2.0758}$, where $\mathrm{P}<0.0001$ and $\mathrm{SE}$ of the estimate was $15.94 \mathrm{~kg}$.

Diagrama de dispersión y modelo de ajuste exponencial del peso corporal desbastado registrado con una balanza electrónica (kg) como una función de la distancia entre la tuberosidad coxal izquierda y derecha (DLRCT; cm). El gráfico se construyó a partir de 496 observaciones. La ecuación de regresión fue $\mathrm{Y}=0,131 \mathrm{X}^{2,0758}$, donde $\mathrm{P}<0,0001$ y el EE de la estimación fue 15,94 kg. 


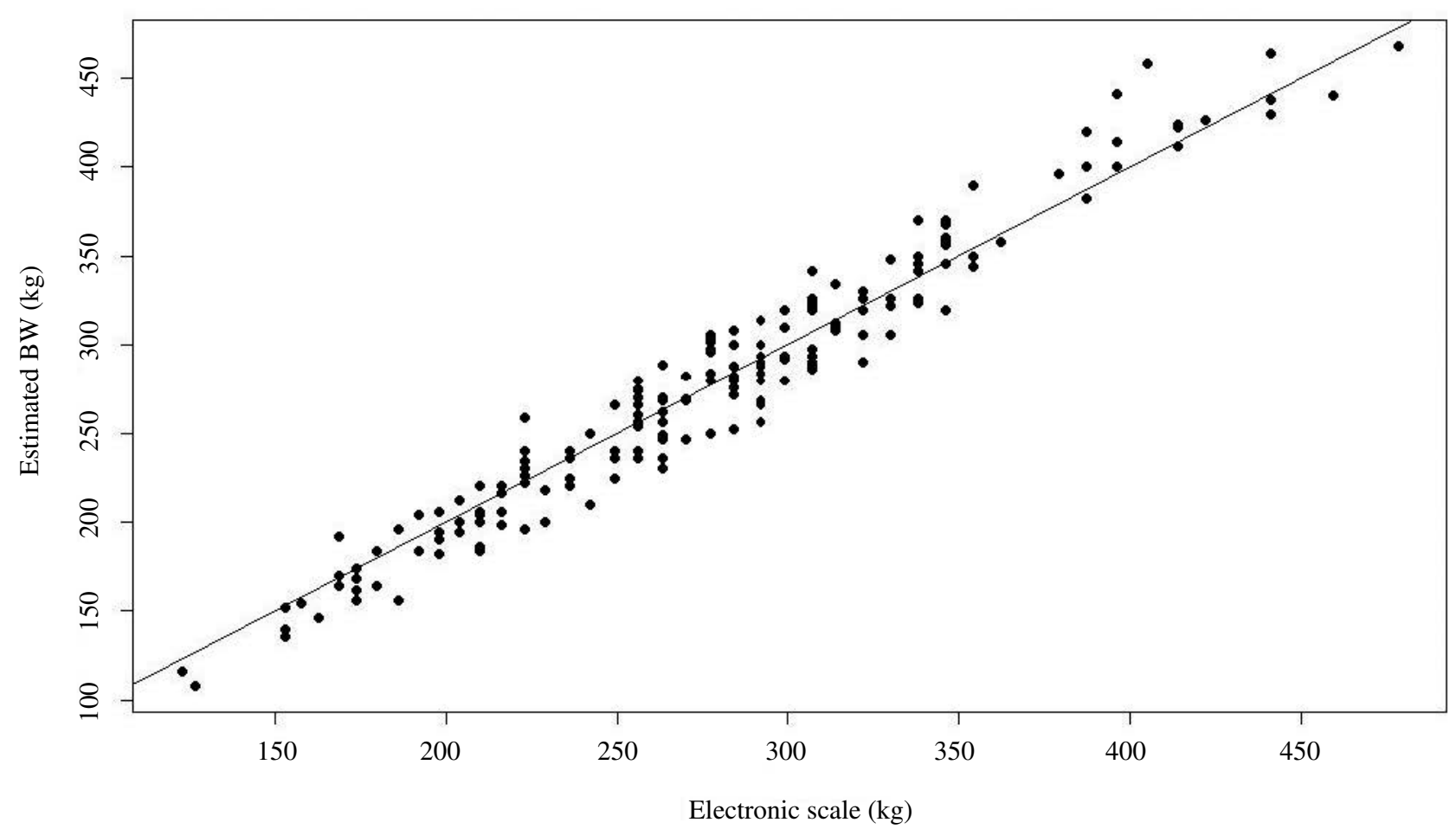

Figure 3. Scatter plot of the shrunk body weight $(\mathrm{kg})$ recorded by the electronic scale and estimated by $\mathrm{Y}=0.131 \mathrm{X}^{2.0758}$, where $\mathrm{X}$ is the distance between the left and right coxal tuberosity (DLRCT; cm). This graph was constructed from 194 observations. Lin correlation coefficient: 0.97, CI (95\%): 0.965 - 0.979 and SE: $0.0037 \mathrm{~kg}$.

Diagrama de dispersión del peso corporal desbastado $(\mathrm{kg})$ registrado con una balanza electrónica y estimado mediante $\mathrm{Y}=0,131 \mathrm{X}^{2,0758}$, donde X es la distancia entre la tuberosidad coxal izquierda y derecha (DLRCT; cm). El gráfico se construyó a partir de 194 observaciones. El coeficiente de correlación de Lin: 0,97, el IC (95\%): 0,965 - 0,979 y el EE: 0,0037 kg.

power regression model. Firstly, upon examination of the Blant-Altman plot (figure 4), it is evident that, for most heifers from $350 \mathrm{~kg} \mathrm{BW}$, there was an underestimation of the SBW when it was predicted by the DLRCT. Dingwell et al (2006) reported BW underestimation when either heart girth tape or hipometer was used to assess BW in heifers heavier than $400 \mathrm{~kg} \mathrm{BW}$. Secondly, this study of model development was performed with heifers of 3 to 21 months of age; however, for its validation, observations were obtained from 5 to 21 month old heifers. Therefore, based on this information, it appears to be inadequate to use the width of hook bones (i.e. DLRCT), as predictor of SBW, in females either younger than 5 months old or heavier than $350 \mathrm{~kg} \mathrm{BW}$ (i.e. $>45 \mathrm{~cm}$ ).

Monitoring the growth of dairy heifers by indirect measurement methods is a time-consuming task. The adoption of new technologies by dairy farmers seems to be associated with labor-saving. In this regard, Turkish researchers demonstrated the utility and the ease of usage of the computer-aided digital image analysis for both the evaluation of body measurements and the estimation of BW by regression analysis of Holstein cows on large-scale dairy farms (Tasdemir et al 2011). In addition, Canadian investigators evaluated the hipometer that uses the external width between hip joints to predict BW and they concluded that hipometer is reliable and easy to use in confinement dairy facilities (Dingwell et al 2006). Similar to other countries, replacement heifers in Argentina are raised on pasture-based production systems. Under this management condition, facilities for dairy cattle handling and working are usually limited, mostly in small and medium-sized farms. In these circumstances, the measurement of the width of hook bones by a handy and simple tool, like the one described herein, may assist farmers to monitor the growth of developing Holstein heifers.

In conclusion, the DLRCT as a predictor of SBW, particularly in heifers $\geq 5$ months of age and $\leq 350 \mathrm{~kg} \mathrm{BW}$ (i.e. $\leq 45 \mathrm{~cm}$ ), is a useful alternative that can be easily applied during any routine practice on replacement heifers (e.g. vaccination) without requiring a squeeze chute. 


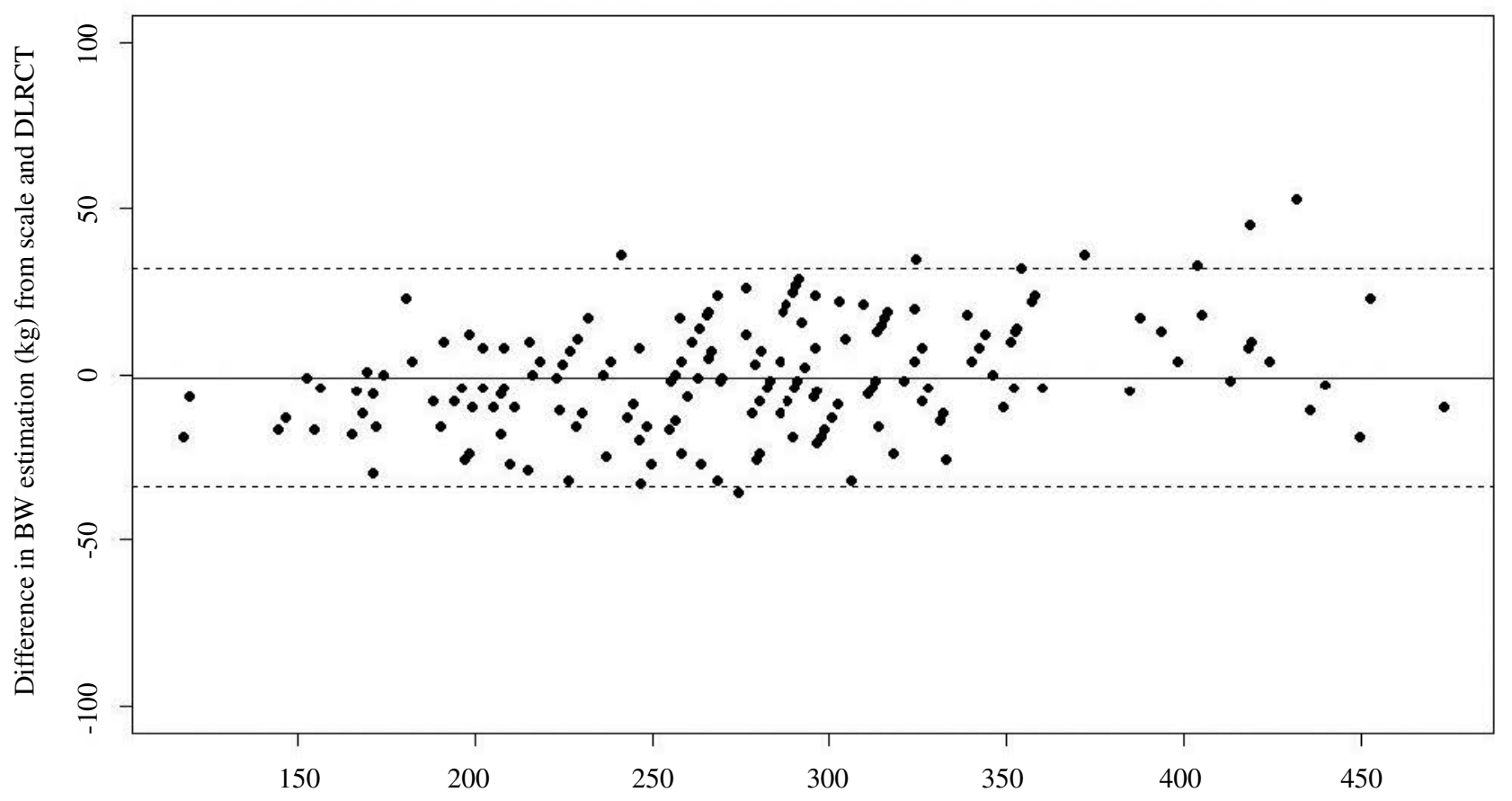

Mean BW estimation $(\mathrm{kg})$ from scale and DLRCT

Figure 4. Bland-Altman plot of the difference and the mean for each pair of shrunk body weight (kg) recorded by the electronic scale and estimated by $\mathrm{Y}=0.131 \mathrm{X}^{2.0758}$, where $\mathrm{X}$ is the distance between the left and right coxal tuberosity (DLRCT; $\mathrm{cm}$ ). The solid line represents the mean difference: $-0.99 \mathrm{~kg}$; the dashed lines represent the $95 \%$ limits of agreement (mean difference \pm 2 SD difference): $-34.2 \mathrm{~kg}$ to $+32.2 \mathrm{~kg}$.

Diagrama de Bland-Altman para la diferencia entre el peso registrado por balanza electrónica y el estimado mediante $\mathrm{Y}=0,131 \mathrm{X}^{2,0758}$ (donde $\mathrm{X}$ es la distancia entre la tuberosidad coxal izquierda y derecha [DLRCT; $\mathrm{cm}$ ]) y la media entre ambos pesos. La línea sólida representa la diferencia media: $-0,99 \mathrm{~kg}$; las líneas punteadas representan el límite de coincidencia del $95 \%$ (diferencia media \pm 2 DE de la diferencia): $-34,2 \mathrm{~kg}$ a $+32,2 \mathrm{~kg}$.

\section{REFERENCES}

Altman DG, JM Bland. 1983. Measurement in medicine: the analysis of method comparison studies. Statistician 32, 307-317.

Dingwell RT, MM Wallace, CJ McLaren, CF Leslie, KE Leslie. 2006. An evaluation of two indirect methods of estimating body weight in Holstein calves and heifers. J Dairy Sci 89, 3992-3998.

Enevoldsen C, T Kristensen. 1997. Estimation of body weight from body size measurements and body condition scores in dairy cows. J Dairy Sci 80, 1988-1995.

Engelken TJ. 2008. Developing replacement beef heifers. Theriogenology 70, 569-572.

Heinrichs AJ, LA Swartz. 1990. Management of dairy heifers. Extension circular 385 Pennsylvania State University. College of Agricultural Sciences, Philadelphia, PA, USA.

Heinrichs AJ, GW Rogers, JB Cooper. 1992. Predicting body weight and wither height in Holstein heifers using body measurement. $J$ Dairy Sci 75, 3576-3581.
Heinrichs J, B Lammers. 1998. Monitoring dairy heifer growth. Publications $N^{o}$ 5M498PS. University Park, Pennsylvania State University, College of Agricultural Sciences, Philadelphia, USA.

Hoffman PC. 1997. Optimum body size of Holstein replacement heifers. J Anim Sci 75, 836-845.

Lin LI. 1989. A concordance correlation coefficient to evaluate reproducibility. Biometrics 45, 255-268.

NRC, National Research Council. 2001. Nutrient requirement of dairy cattle. $7^{\text {th }}$ ed. National Academic Press, Washington, DC, USA.

$\mathrm{R}$ version 2.15.0. 2012. The R Foundation for Statistical Computing, Vienna, Austria.

SAS. 2004. SAS OnlineDoc 9.1.3. SAS Institute Inc.,Cary, NC, USA.

Tasdemir S, A Urkmez, S Inal. 2011. Determination of body measurements on the Holstein cows using digital image analysis and estimation of live weight with regression analysis. Comput Electron Agric 76, 189-197. 